\title{
A ESTEREOTIPIA DA CULTURA AFRICANA NAS ESCOLAS
}

DOI: 10.47224/revista master.v6i11.155

\author{
Danilo Faria de Moura \\ Maria Luiza de Borba Alves \\ Alline Naves Teodoro \\ Ana Laura Machado de Sousa \\ André Felipe Angelica de Brito \\ Camila Fernandes de Souza \\ Larissa Esther de Freitas Da Silva \\ Maria Luiza Pires Peixoto \\ Myllena Sthéfany Dias Santos \\ Simei Resende Costa
}

e-mail:danilofmoura@yahoo.com.br

\section{Resumo}

Esse artigo descreve a uniformidade do ensino da cultura afro-brasileira nas instituições escolares que se apresenta de forma estereotipada, trazendo consigo uma deficiência na percepção dos alunos quanto ao modo de tratamento as pessoas negras. Descreve similarmente os meios para se alcançar uma educação igualitária que não carregue consigo nenhum tipo de segregação. As pesquisas relatadas foram desenvolvidas por meio da metodologia da problematização com o Arco de Maguerez e de uma pesquisa bibliográfica para o embasamento teórico dos assuntos apresentados. Valeuse de uma pesquisa feita com professores atuantes e que igualmente compartilham de experiências negativas quanto a aplicação da temática em seu cotidiano. É apresentado também algumas práticas pedagógicas visando a melhoria do trabalho com a diversidade cultural no âmbito escolar, o que facilitará o modo como os educadores enfrentam e abordam o tema, racismo em sala de aula. Conclui-se que o docente precisa participar das mudanças, estando na linha de frente, impulsionando as pessoas a quem ele exerce influência, entendendo que precisa ter a iniciativa de procurar uma formação continuada para suprir as lacunas de conhecimento sobre como ensinar sobre questões raciais e culturais, se livrando de rótulos e estereótipos.

Palavras-chave: Racismo; Diversidade cultural; Escola; Educação.

\begin{abstract}
This article describes the uniformity of teaching of afro-brazilian culture in class institutions that presents itself during a stereotyped way, bringing with it a deficiency in students' perception of the way during which black people are treated. It similarly describes the means to realize an egalitarian education that doesn't carry with it any quite segregation. The reported researches were developed through the methodology of problematization with the Arch of Maguerez and a bibliographical research for the theoretical basis of the presented subjects. It had been supported a survey administered with active teachers who also share negative experiences regarding the appliance of the theme in their daily lives. It also presents some pedagogical practices aimed toward improving the work with cultural diversity within the school environment, which can facilitate the way during which educators face and address the difficulty, racism within the classroom. It's concluded that the teacher must participate within the changes, being at the forefront, pushing the people on whom he exerts influence, understanding that he/she must take the initiative to hunt continuing education to fill the knowledge gaps on the way to teach about racial and cultural, getting obviate labels and stereotypes.
\end{abstract}

Keywords: $\quad$ Racism; Cultural diversity; School; Education. 


\section{INTRODUÇÃO}

É indiscutível que o Brasil é uma nação com grande diversidade de culturas e etnias. Africanos, índios, europeus, entre outros povos, fazem parte da ascendência de sua linhagem. Tal multiculturalidade é evidentemente refletida nas instituições de ensino, onde a vida, principalmente a escolar brasileira, é composta de uma ambiguidade de histórias, famílias e situações financeiras.

[...] a escola precisa abandonar o modelo no qual se esperam alunos homogêneos, tratando como iguais os diferentes, e incorporar uma concepção que considere a diversidade tanto no âmbito do trabalho com os conteúdos escolares quanto nas relações interpessoais. (ARAÚJO, 1998, p. 44)

Incluso nesse universo pluricultural se encontra o educador, que se faz de extrema importância para que todos os discentes presentes nos espaços escolares convivam em máxima harmonia possível, sem que problemas de racismo, principalmente contra grupos de negros, sejam evidenciados e superestimados. Em face à tal realidade, é significativo compreender que, apesar de o corpo docente abordar as problemáticas referentes ao racismo, em sua grande maioria as tratativas com o tema são bastante superficiais e enfadonhas, considerando que os acontecimentos de discriminação racial não têm diminuído, e sim, ampliado.

Adido a esta situação, evidencia-se que os livros didáticos não possuem demasiada explanação histórica de fatos em que negros são apresentados como grandes heróis, com seus feitos lendários. Em sua grande maioria, apresentam-se negros como escravos, servos, rebeldes e desrespeitosos quanto à classe superior, branca. Esta concepção traz consigo uma carga emocional imensa sobre os alunos que, mal instruídos, podem considerar esses fatos correspondentes mesmo atualmente, o que estimula o racismo.

A criança não vê nele seu cotidiano representado, mas muitas vezes percebe a ausência de pessoas negras representadas ou ocupando posições subalternas. Isso resulta em uma sensação de estranheza, podendo levar a criança negra a autodepreciação, e a construção de uma autoimagem negativa. (SOUZA et al, 2002, p. 44).

O principal foco deste artigo é observar os efeitos da aplicação da conscientização afrodescendente nas instituições de ensino e o quanto têm sido estereotipadas na educação brasileira atual. Serão observados os trabalhos que abordam esse assunto, assim como as características históricas e sociais e ambientes escolares.

"O mundo antigo está cheio de denominações racistas" Platão (428-348 a.C). "Em sua obra a intitulada $A$ república, Platão define um estado ideal onde os melhores se relacionam com os melhores, o ouro não se mistura ao bronze" (PLATÃO, 2007, p. 242 apud DA SILVA, 2016, p. 12). É possível perceber que, desde tempos remotos, perdura uma preocupação dos filósofos quanto a pureza, preocupação essa que era sempre seguida de perto pelo segregamento dos mais severos. Perceptível também é o fato de que essas mesmas atitudes e comportamentos se estenderam até as comunidades modernas e atuais, onde bárbaros continuam existindo e perpetuando tais pensamentos retrógrados.

O presente artigo é resultado de atividades desenvolvidas no Curso de Pedagogia, no componente curricular Projeto Integrador VII Educação das Relações Étnico-raciais e história e cultura afro-brasileira, africana e indígena, do 60 (sexto) e 70 (sétimo) períodos, do primeiro semestre de 2020 .

As pesquisas aqui relatadas foram desenvolvidas por meio da Metodologia da Problematização com o Arco de Maguerez norteadas pela temática: a estereotipação das práticas de ensino da cultura afrodescendente das escolas na cidade de Araguari/MG. Empregou-se o uso de um questionário respondido por alguns professores para a observação da realidade e de revisão bibliográfica para o embasamento teórico dos assuntos apresentados.

As ações pedagógicas diante da lei $\mathrm{n}$ o 10.639/03 podem ser vistas como uma medida para impulsionar grandes mudanças na escola e na sociedade, fazendo com que as crianças reflitam desde cedo sobre a discriminação racial, a diversidade étnica, gerando debates, estimulando valores e comportamentos de 
respeito e solidariedade com outras culturas (LIMA, 2016, p. 15).

Muito se discute sobre o papel do professor diante dessa colocação, entendendo que é importante que o profissional da educação saiba implementar e explicar para aos educandos sobre esse tema, sem excluir nuances importantes, apresentando todos os tópicos possíveis, não apenas o que já é tipicamente conhecido, pois um povo traz consigo cultura e saberes que devem ser perpassados com maestria.

Entretanto, colocar isso em prática exige uma imposição maior do professor, pois em muitas instituições datas comemorativas advindas da cultura negra são trabalhadas em uma semana, no máximo. Nesse curto espaço de tempo o professor não consegue entregar todo conteúdo necessário para que exista uma reflexão dos alunos e a semana acaba por se resumir em fazer cartazes, ler textos e fazer redações.

O objetivo geral deste artigo é investigar sobre a aplicação e transferência de conhecimentos referentes à temática História e Cultura AfroBrasileira nos currículos de instituições de ensino no município de Araguari/MG. Os objetivos específicos compreendem a análise das práticas educativas referentes a essa temática durante o calendário anual escolar; a inserção efetiva da Lei 10.639/03 no currículo escolar e propor alternativas para que as instituições de ensino fomentem positivamente essa temática.

A partir desse ponto, serão apresentados, sequencialmente, a observação da realidade, as justificativas, a delimitação da problemática, os pontos chaves elencados, o desenvolvimento a partir da teorização, as hipóteses de solução, os relatos de aplicação à realidade e as conclusões finais.

\section{2}

\section{OBSERVAÇÃO DA REALIDADE}

Diante da atual situação da sociedade, com o surgimento de uma pandemia global (COVID-19), todos os campos sociais tiveram que se adaptar à uma nova realidade para continuar atendendo a população. Sendo assim, as escolas tiveram que optar por aulas remotas, e, em virtude desse fato, as observações deste estudo não puderam ser feitas presencialmente, tendo como alternativa a construção de um questionário online direcionado a professores das redes pública e privada de ensino do município de Araguari/MG. O questionário de nome Educação das Relações Étnico-raciais e História e Cultura Afro-brasileira teve como base a aplicação da Lei 10.639/03, que tem como finalidade as DCNs (Diretrizes Curriculares Nacionais) para a Educação das Relações Étnico-Raciais e para o Ensino de História e Cultura Afro-Brasileira e Africana.

O questionário obteve ao todo oito participantes, com idades entre 20 e 65 anos, a maioria dos profissionais atuantes em escolas particulares com alunos dos primeiros anos do Ensino Fundamental. Algumas interrogações contidas no formulário ganharam destaque, principalmente o que tange às manifestações artísticas das culturas indígenas e afro-brasileiras e como são trabalhadas em sala de aula.

A pesquisa contou com diversas perguntas acerca da problemática racial, entrando em questões sobre acervo biográfico, demonstrações sobre a cultura e tradição dos povos e como as questões são trabalhadas no ambiente escolar, pois "[...] ao se falar em educação, não se pode ter em vista apenas a escolarização, mas também o preparo para a tolerância e a diversidade, fundamental para uma sociedade com pluralidade étnica" (SILVA, 199, p. 141 apud DA SILVA, 2007, p. 43).

Com os dados obtidos foi possível perceber que, mesmo em escolas particulares, as questões raciais ainda não estão sendo tratadas em seu devido valor, apresentando um pequeno percentual de instituições que trabalham as Leis 10.639/03 e 11.645/98 em seu Projeto Político Pedagógico (PPP), onde apenas $37,5 \%$ foi realmente consolidado.

\section{JUSTIFICATIVA}

A população brasileira convive com a inexistência de tato para tratar as questões estereotipadas da cultura africana. Muitas vezes o educador não está apto para iniciar essa abordagem em virtude da complexidade do assunto.

O sistema educacional está imerso em sociedade preconceituosa e estagnada e deve focar esforços para preparar pessoas que não adotem essa concepção. Cabe aos futuros docentes, e os atuais, abordar as temáticas étnico-raciais nas escolas, mas para isso é importante entender a fundo a temática, 
como descreve os Parâmetros Curriculares Nacionais (PCN's), que esclarece sobre a Pluralidade Cultural que deve ser estudada e valorizada. Esses parâmetros estabelecem a todos os envolvidos a oportunidade de conhecimento origens do povo brasileiro, representações de grupos culturais específicos, e assim a compreensão das diversas culturas que há no país. Além do mais, propiciam uma ampla visão do seu próprio valor, estabelecendo conhecimentos e vivências que apure a percepção de preconceito e discriminação que recaem sobre esse povo, para que, estudandoas e vivenciando-as, os alunos possam desenvolver atitudes de não aceitação dessas práticas.

Faz-se importante a estruturação dessa possibilidade na promoção de uma relação importante em sala de aula, sabendo que os temas e subtemas que podem, e devem, ser tratados sobre as temáticas étnico-raciais, possibilitam que o grupo desconstrua e reconstrua conceitos por meio de debates, proporcionando reflexões críticas que os levarão a formar a sua opinião de forma clara sobre as diversidades culturais no qual estão inseridos.

Para Barbosa (2007, p. 26) "há povos que conservam e transmitem seus conhecimentos pela escrita, outros transmitem pela oralidade. Isso não quer dizer que um seja superior ou inferior a outro. Apenas são diferentes."

A abordagem dessa temática no contexto de formação de professores no ensino superior é de estimada relevância, levando em conta como se pode agir em meio a virtude das dificuldades que há nas instituições de ensino, já que estas ainda não apresentam formas de abordagens relevantes e significativas para a não aceitação de práticas preconceituosas normatizada pela LDB e a Lei $10.639 / 03$, que propõe novas diretrizes curriculares para o estudo da história e cultura afro-brasileira e africana.

Deve-se considerar que as instituições de ensino deveriam, a partir da Educação Infantil, iniciar o ensino de história e cultura africana, pois é necessário fazer com que a criança, mesmo pequena, perceba a diversidade que há em sua volta, pois ela pode desenvolver essa capacidade intrínseca de formar competências significativas. Essas competências estão diretamente ligadas à concepção do sujeito em resolver situações problemas do cotidiano, até mesmo o reconhecimento da diversidade e a valorização dos aspectos físicos africanos, dentre muitos outros.

Analisando a necessidade da mediação do adulto e a abordagem da temática de um jeito mais simples, porém significativa, é relevante inserir a temática em práticas diárias, como brincadeiras, leitura e música, levando a criança à concepção de como lidar com as diferenças com sensibilidade e equilíbrio. A abordagem não deve se limitar à projetos com duração definida ou em datas comemorativas, como ainda é encontrado sendo praticado em muitas instituições de ensino. É preciso que, desde a infância, seja trabalhado a familiaridade com a diversidade, através principalmente da leitura de livros que abordem à diversas histórias relacionadas às culturas existentes no país, e, assim, ampliar para o conhecimento sobre os aspectos culturais.

\begin{abstract}
Qualquer classificação pautada por estereótipos traz em si uma identidade social que se produz no interior de uma dada realidade cultural. Tais classificações convertem-se nas imagens afirmativas ou não, transmitidas pelos grupos em interação dentro de determinadas tradições culturais. $\mathrm{O}$ autor defende que os estereótipos envolvem um processo cognitivo. Ou seja, os indivíduos que pertencem a um determinado grupo aprendem a simbologia que envolve a estereotipia e reproduzem-na ao longo da história, com isso, se mantêm as diferenças identitárias entre os grupos. Um estereótipo não é um estereótipo social até e a não ser que seja amplamente partilhado dentro duma entidade social. Isso significa dizer que a consolidação de uma imagem estereotipada depende fundamentalmente de um consenso dos indivíduos que constituem um grupo. (TAJFEL, 1982, P. 176, apud FLEURI, 2006, p. 499)
\end{abstract}

Esse artigo foi desenvolvido como auxílio de instrumento de reflexão e pesquisa para que seus leitores reflitam sobre a influência das práticas mediadores referentes às diversidades culturais desde a primeira infância, o que podem ser prescritas como uma manutenção preventiva para o futuro das crianças. Essa abordagem contribui para que, quando chegarem à idade adulta, esses cidadãos não sejam notificados por praticar atos de preconceito, racismo e discriminação com aqueles que são diferente pelo aspecto de raça, cor e 
posicionamento social, mas, diferentemente, que cheguem a essa fase respeitando essa diversidade e possam estar em uma posição de igualdade, mesmo que a própria sociedade não acredite nessa concepção.

É evidente que a educação têm passado por grandes mudanças, seja pelos avanços tecnológicos ou pela busca de novas abordagens educacionais, fazendo com que a autonomia dos educandos seja despertada e, assim, com esse novo recurso amplo, pode-se ter uma nova perspectiva e um novo olhar para adequação dessa promulgação das leis que instituem o ensino da história da cultura afrobrasileiras e africana, rompendo satisfatoriamente as resistências provenientes de preconceitos e a falta de formação específica dos docentes.

A partir da pesquisa realizada, direcionadas pelas lacunas identificadas pelos resultados do formulário proposto na observação à realidade, é notório o quanto a escola precisa rever essa relação entre a construção e a necessidade do aprofundamento da abordagem e estudo da história e da cultura afrobrasileira e africana. Deve rever ainda sua influência na sala de aula, abrangendo abordagens e estratégias pedagógicas significativas que viabilizem a realização de um trabalho e convívio eficiente e que proporcione aos docentes e discentes uma aprendizagem de qualidade alinhada aos direitos humanos.

\section{4}

\section{PROBLEMA}

O grande aspecto que impulsionou a observação a realidade é que, para a maioria das questões, as respostas foram que a escola ainda está em fase de desenvolvimento de ações e políticas que abarquem a história e cultura africana e afro-brasileira. Isso acaba sendo bastante preocupante, pois evidencia que as escolas não trabalham o tema como determina a legislação.

As grandes questões são: por que não trabalhar a cultura africana nas escolas? Por que um assunto tão importante é tratado com desdém pelas instituições? São perguntas que precisam ser repensadas e resolvidas. A cada dia surgem novos casos de alunos sofrendo preconceito nas escolas, e essas não tomam as providências devidas para inibir efetivamente essas ações. Esse é um tema que deve estar em evidência nas aulas e sempre ter sua importância durante todo desenvolvimento do aluno na escola.

Quando é abordado sobre a cultura africana dentro de uma escola depara-se com alguns empecilhos, pois trabalhar essa cultura em sala de aula é sempre um desafio para um professor, que em alguns casos não tem apoio do corpo docente estudantil.

Os resultados obtidos pela pesquisa realizada possibilitaram direcionar as atenções para compreender melhor como as escolas trabalham a temática em suas salas de aula. Destaca-se que, em relação a cultura africana, não foram apresentados aspectos tão positivos, pois o processo para a implementação das atividades nas escolas ainda está em andamento imerso em um processo lento.

\section{PONTOS-CHAVE}

Infelizmente, a instrumentalização para a aplicação dessas políticas não acompanhou a necessidade das instituições de ensino, pois existe a ausência de abordagem com profundidade dos conteúdos necessários sobre o assunto, sabe-se que os livros didáticos ainda são pouco suporte necessário para os educadores, onde possuem limitações quando é preciso falar sobre a História e cultura Afro-brasileira e Africana em sala de aula. (LIMA, 2016, p. 18)

Para Lima falta embasamento teórico, tanto para alunos quanto para o educador, que, por vezes, acaba por ter que complementar os conteúdos presentes nos materiais que utilizam diariamente. Felizmente alguns ainda buscam essa implementação, enquanto uma parcela termina por seguir somente a pouca informação presente em livros didáticos. Com base no que se vê quando a questão é o papel do professor pode-se esperar um empenho desesperadamente menor nos outros componentes das escolas como será destacado nos pontos-chave.

A relevância de detectar os pontos-chave é a maior noção dos fatores ocorrentes para mais eficácia na compreensão de possíveis causas da existência do problema, facilitando o encontro de evidente solução. Entende-se que os pontos encontrados nas análises dos questionários respondidos pelas professoras, são:

Falta de conscientização com todos os funcionários sobre a importância da lei e suas abrangências em algumas escolas; 
- Pouco diálogo construído coletivamente na comunidade escolar em casos de ocorrências de situações discriminatórias e racistas;

- Efetivou-se envolvimento das famílias nas atividades étnico racial em poucas escolas;

- Falta de propostas de trabalho pedagógico para diminuir 0 uso de apelidos depreciativos para negros e outros grupos socialmente discriminados no ambiente escolar;

- Na maioria das escolas o trabalho didático pedagógico com as leis relacionadas ao Ensino da História e Culturas Africanas e Afro-brasileira e dos Indígenas não estão completamente incorporados no PPP escolar;

- Falta de atividades no plano anual da escola, no trabalho com as questões étnico raciais.

- Dentre os citados anteriormente, destacase três como principais. São estes:

- Pouco diálogo construído coletivamente na comunidade escolar em casos de ocorrências de situações discriminatórias e racistas;

- Na maioria das escolas o trabalho didático pedagógico com as leis relacionadas ao Ensino da História e Culturas Africanas e Afro-brasileira e dos Indígenas não estão completamente incorporados no PPP escolar;

- Falta de propostas de trabalho pedagógico para diminuir o uso de apelidos depreciativos para negros e outros grupos socialmente discriminados no ambiente escolar.

Observando esses pontos-chave aprofundou-se teoricamente para maior conhecimento acerca do assunto trabalhado.

\section{6}

\section{TEORIZAÇÃO}

Em um consenso unânime é de se esperar que a escola seja um local seguro para o crescimento intelectual e pessoal de um indivíduo, porém infelizmente a realidade de crianças e jovens negros dentro do âmbito escolar pode ser extremamente depreciativa e traumatizante, pois nesta etapa da vida o sujeito está em sua primeira construção de identidade, ou seja, "a ampla e consistente introdução de um indivíduo no mundo com objetivo de uma sociedade ou de um setor dela." (BERGER; LUCKMANN, 1976, p. 46)

Visto que o centro deste artigo se baseia na temática da estereotipação da cultura afro-brasileira nas escolas, fazse necessário refletir como funcionam os estereótipos seguido de preconceitos e, nesse sentido, entender como as representações racistas se fundamentam em uma época em que se espera que tenha alcançado um nível de desenvolvimento e compreensão acerca das diferenças.

O preconceito trata-se de quando determinado indivíduo ou grupo, observando a diversidade existente, se coloca em direito de formar opiniões de outros com base em seus achismos, e isto muitas vezes leva às práticas discriminatórias. As vítimas destes ataques físicos ou psicológicos são vistas por parte da sociologia como grupos minoritários, isto é, grupo vulnerável e/ou de minorias.

Em vários estudos apresenta-se a existência de dois tipos de preconceito expresso, o clássico, apresentado nitidamente com tratamentos rudes direcionados a alguém, e o preconceito moderno, nem sempre demonstrado ou com finalidade velada que acaba sendo despercebida. "Esta forma oculta nos engana, nos fazendo pensar que houve redução do preconceito, só porque não foi nítido". (PEREIRA; TORRES; ALMEIDA, 2003, p. 98)

Visto que nenhum segmento da sociedade está isento do racismo, ele está inclusive de maneira implícita, no ambiente escolar, temos a escola como instituição formadora de saberes escolares e, também, sociais e culturais. Diante disso, a cultura escolar no processo de construção de identidades sociais, tendo a escola como mais um espaço importantíssimo na construção da empatia e processo de humanização, tem grande peso.

O processo escolar de cada indivíduo é um considerável momento no caminho de construção da identidade negra, e infelizmente, reforça-se estereótipos e reproduções negativas sobre esse fragmento étnico/racial e o seu padrão estético. O ser humano se comunica por meio do corpo, o corpo fala e ele é construído biologicamente e culturalmente na cultura e na história.

O corpo fala a respeito do nosso estar no mundo, pois a nossa localização na sociedade dá-se pela sua mediação no espaço e no tempo. Estamos diante de uma realidade dupla e dialética: ao mesmo tempo que é natural, o corpo é também simbólico. Ele pode ser a referência revolucionária da universalidade do homem no contraponto crítico e contestador à coisificação da pessoa e à exploração do homem pelo homem na 
mediação das coisas. (MARTINS, 1999, p. 54)

O artigo de Lima (2016) também traz à luz questões acerca da lei 10.639/03 que torna obrigatório o ensino da cultura Afro-brasileira e Africana na educação. Desde crianças até a formação no ensino médio, a cultura africana sempre é trabalhada em uma única semana letiva. A proposta da lei tem como objetivo fazer o educando refletir sobre práticas discriminatórias, preconceito, racismo e outras questões tais como a desigualdade social.

Diante das leituras podemos observar que ainda existe uma grande resistência em relação a prática dessa lei. Algumas dificuldades são encontradas, com destaque para o fato do despreparo e desconhecimento dos professores com o tema, o pouco material existente de estudo sobre a história e cultura Africana e Afrobrasileira. (LIMA, 2016, p. 15)

Mesmo que pareça que a lei visa apenas o âmbito escolar, sua abrangência chega até pautas como exclusão de apelidos depreciativos com os colegas e conhecidos. Após a criação dessa lei, em 2003, surgiram muitos movimentos com essa proposta, como o projeto A cor da cultura, de 2004, que conta com materiais didáticos adequados complementares para professores da rede pública do ensino brasileiro, com o objetivo de valorizar aspectos culturais e saberes advindos da cultura Afrobrasileira e Africana.

Entretanto, mesmo hoje, tantos anos depois da implantação da lei, não se vê de maneira notória uma mudança na forma em que a educação aborda a história e cultura africana. Poucos são os professores que possuem afinidade com o tema para criar outras atividades e projetos e, mesmo assim, ainda precisam do aval da instituição, que frequentemente opta por continuar na zona de conforto, impedindo a proliferação de uma pedagogia mais inclusiva e que valorize a diversidade ética em sua totalidade.

Sabe-se que a responsabilidade em combater essa realidade de etnias e desvalorização de diversidade não é somente da escola, mas da sociedade como um todo. Para minimizar os efeitos da falta de conscientização sobre a história e cultura africana, as escolas precisam munir-se de estratégias significativas, pois elas têm a responsabilidade de formar e orientar cidadãos. Mas, o que é visto em artigos e noticiários, e presenciado e encontrado nas instituições de ensino, é a falta de conscientização camuflada, levando, assim, a ausência e ao silêncio na esfera escolar sobre o assunto, que promove discriminação e uma imagem estereotipada do indivíduo sobre si e o mundo ao seu redor. Uma outra maneira para mudar esta situação, ou amenizá-la, é a escola estar atenta para suas práticas, comprometendose com a diversidade.

A escola deve estar comprometida com projetos que visem mudanças nas atitudes dos alunos em relação ao combate do racismo e a conscientização do mesmo. Assim, a escola irá promover o bem de todos, sem preconceitos de origem, raça [...] $E$ quaisquer outras formas de discriminação. (BRASIL, 1988, p. 9)

Com base em estudos e leituras de autores sobre este assunto, destacou-se a possibilidade de conscientização sobre história e cultura afro nas escolas, levando em conta o trabalho pedagógico para questões étnicoraciais, pois este é importante, não só no auxílio aos educandos à compreensão que há diferença entre indivíduos, povos e nações, porque possibilita que possa haver um desencadeamento de pensamento mais respeitoso entre as pessoas, independentemente de suas características e origens. Assim a escola demonstrará o cuidado e o comprometimento com a diversidade. "A lei 10.639/03 pode constituir-se como uma ferramenta importante para o combate ao racismo, e consequentemente, para a superação do quadro de desigualdades raciais e sociais presentes na sociedade brasileira" (ROCHA, 2011, p. 37).

No momento em que as questões étnicas são trabalhadas dentro da sala, desde os primeiros anos da vida escolar, usando práticas simples de contação de histórias, devese enfatizar a cultura africana e afro-brasileira, gerando assim, desde a infância, a familiaridade com a diversidade, ampliando o conhecimento sobre os aspectos culturais, pois é de responsabilidade da escola visar a integridade o comprometimento com a questão racial.

A diversidade de classe, sexo, idade, raça, cultura, crenças etc., presentes na vida da escola e pensar (e repensar) o currículo e os conteúdos escolares a partir dessa realidade tão diversa. A construção de práticas democráticas e não preconceituosas implica o reconhecimento do direito à diferença e isso inclui as diferenças raciais. (GOMES, 2001, p. 87)

Combater a desigualdade racial e buscar conscientizar sobre o assunto é reconhecer a importância do tema e, assim, auxiliar na criação de referências positivas para a população negra reverter um quadro que, historicamente, sempre depreciou tal segmento. Faz-se necessária uma autoanálise, levando em conta a noção 
de que o papel principal dos educadores na escola não é o de reproduzir valores e crenças pessoais, mas colaborar com a formação positiva dos alunos, como prevista no PPP das instituições de ensino e na Constituição Federal, garantindo a liberdade de cada um.

Mediante a todos os argumentos apresentados, entendese que existe uma problemática a ser elucidada quanto à temática em exposição. Dessarte, foi-se utilizado para a fundamentação teórica, um vasto repertório de materiais científicos encontrados em livros didáticos disponíveis em bibliotecas virtuais, assim como artigos contidos em repositórios online, o que, consequentemente, orienta para as hipóteses de solução detectadas para a estereotipação do ensino da cultura afro.

O sucesso das políticas públicas de Estado institucionais e pedagógicas, visando a reparações, reconhecimento e valorização da identidade, da cultura e da história dos negros brasileiros depende necessariamente de condições físicas, materiais, intelectuais e afetivas favoráveis para o ensino e para aprendizagens; em outras palavras, todos os alunos negros e não negros, bem como seus professores, precisam sentir-se valorizados e apoiados. Depende também, de maneira decisiva, da reeducação das relações entre negros e brancos, o que aqui estamos designando como relações étnico-raciais (BRASIL, DCNs, 2004, p. 8)

Deve-se considerar que nenhuma teoria tem sua efetividade enquanto se posicionar apenas em verbalidade. É crucialmente importante a compreensão de que as atitudes sobressaem os pontos de vista, se estes se mantiverem apenas no campo das ideias. As mudanças, e consequentemente as melhorias de um país culturalmente decadente, virão somente se todos os envolvidos na educação se prontificarem a cumprir seus respectivos papéis.

\section{A IMPORTÂNCIA DAS LEIS 10.639/03, 11.645/08 E SUAS ABRANGÊNCIAS EM ALGUMAS ESCOLAS}

Considerando o aspecto da falta de conhecimento e conscientização das leis que visam a questão racial nas escolas (Leis 10.639/03 e 11.645/08), e tendo como ilustração os dados obtidos com a pesquisa, é possível deduzir que o não cumprimento destas leis é um grande marco ilustrador da injustiça que a cultura negra é obrigada a se submeter no país, sendo sempre marginalizada e estereotipada.

A Lei 10.639/03 versa sobre o ensino da história e cultura afro-brasileira e africana, ressaltando a importância da cultura negra na formação da sociedade brasileira. Sobre a proposta trazida por essa mesma lei, Bakke (2005, p. 98) considera de grande importância para a área da educação, pois leva aos meninos e meninas informações sobre aspectos da cultura brasileira que, muitas vezes, são deixados em segundo plano pelos educadores e pelas próprias escolas. As crianças aprendem mais sobre o assunto que geralmente é deixado de lado.

A iniciativa visa trazer para a escola a discussão a respeito da temática da cultura e da história da África e afro-brasileira com o intuito de desenvolver, entre os estudantes em geral, seja afrodescendente ou não, consciência política e histórica, valorização e respeito à diversidade, fortalecimento e da identidade afrodescendente e questionamento do racismo. (BAKKE, 2005, p. 92)

De acordo com Dos Santos Cavalleiro (2014, p. 25) "o silêncio do professor facilita novas ocorrências de racismo, reforçando inadvertidamente a legitimidade de procedimentos preconceituosos e discriminatórios no espaço escolar". Essa é uma atitude contraditória do papel do professor no caráter formador de opinião, entendendo-se que a partir do momento que o docente fecha os olhos para as atitudes preconceituosas em sala de aula, ele compactua com tal comportamento, influenciando seus alunos.

Faz-se extremamente viável que as escolas atendam, o quanto antes, as propostas das leis vigentes, sendo pela legislação uma obrigação das instituições de ensino e uma questão de valores éticos e morais que utopicamente é dever de todos. Pois, "se a educação não transforma sozinha a sociedade, sem ela tampouco a sociedade muda" (FREIRE, 1997, p. 67), elevando a percepção da importância das políticas raciais e o conhecimento dos âmbitos legais desta problemática. 


\section{A FALTA DE DIÁLOGO ENTRE A COMUNIDADE ESCOLAR EM CASOS DE OCORRÊNCIA DE SITUAÇÕES DISCRIMINATÓRIAS}

$\mathrm{Na}$ maioria das escolas o trabalho didático pedagógico com as leis relacionadas ao Ensino da História e Culturas Africanas e Afro-brasileira e dos indígenas não estão completamente incorporados no PPP escolar. Freire (1997) destaca que o professor deve ser inventor e tem que sempre estar se reinventando para que, assim, consiga transmitir o melhor aos seus alunos, pois dentro da sala de aula o professor e mediador.

É de extrema importância o envolvimento da sociedade na vida escolar das crianças, visto que a educação é um fato muito importante na vida do ser humano, pois com conhecimento é possível se desenvolver melhor no cotidiano social.

A cultura afro está sendo inserida nas escolas como lentidão, o projeto de lei 10.639 determina que o ensino história e da cultura afro-brasileira nas escolas de ensino médio e fundamental, foi instituído desde 2003 nas DCNs, mas até o presente momento esse processo não está instituído na maioria das escolas. 0 que se observa nas escolas é que essa cultura é implantada por meio de datas comemorativas, como o Dia da Consciência Negra, método que não é eficaz.

Negro torna-se, então, sinônimo de ser primitivo, inferior, dotado de uma mentalidade pré-lógica. $E$, como o ser humano toma sempre o cuidado de justificar sua conduta, a condição social do negro no mundo moderno criará uma literatura descritiva dos seus pretendidos caracteres menores. 0 espírito de muitas gerações europeias foi progressivamente alterado. A opinião ocidental cristalizou-se e admitiu de antemão a verdade revelada: negro = humanidade inferior. À colonização apresentada como um dever, invocando a missão civilizadora do Ocidente, competia à responsabilidade de elevar o africano ao nível dos outros homens. (MUNANGA, 1986, p. 9)

Ressalta-se que os pais devem estar presente na vida escolar de seus filhos para que eles possam ter conhecimento do que está sendo ensinado. Inserir a cultura afro na escola é de suma relevância, pois as crianças já aprendem que a cultura ou a cor da pele não tornam o outro inferior, os pais e professores podem dar a melhor educação em relação ao respeito para com o ser humano e sua a cultura.

\section{A EFETIVAÇÃO DO ENVOLVIMENTO DAS FAMÍLIAS NAS ATIVIDADES ÉTNICO RACIAIS}

Um ponto presente nas investigações deste estudo consta na participação da família no aspecto racial nas escolas, tendo como precedente o relato sobre o papel da escola e do professor. Nesse caso, faz-se importante salientar que a relação família/escola vem sendo objeto de estudo há muito tempo, contendo indagações referentes ao sucesso das crianças na carreira acadêmica, entre outros aspectos relacionados ao ingresso escolar.

$\mathrm{Na}$ tentativa de eximir da culpa com relação ao seu fracasso em sua função em educar, a escola desenvolve preconceitos que atingem a classe trabalhadora, principalmente com relação às famílias pobres e negras, marginalizando suas crianças e depositando nelas toda a sorte de distúrbios. (PATTO, 1999, p. 182)

Tendo como princípio este pré-julgamento e exclusão, é de se imaginar como funciona o relacionamento entre as famílias negras e sua presença na escola, uma vez que é de cunho geral que essas famílias precisam ser representadas nesse contexto escolar, e que se faz necessário abordar o tema racial e a cultura afro-brasileira em projetos e atividades culturais e pedagógicas.

A escola deve fazer as adequações necessárias, visto que essa situação tende a transparecer uma reprodução das desigualdades entre negros e brancos no contexto social. "Assim, a família protela por um tempo maior o contato com o racismo da sociedade e com as dores e perdas dele recorrentes, silencia um sentimento de impotência ante o racismo da sociedade, que se mostra hostil e forte." (DOS SANTOS CAVALLEIRO, 2004, p. 100)

Sabe-se que é no ceio familiar que a educação se inicia, então é essencial que a família participe da vida escolar dos filhos e que estejam sempre envolvidos em todos os assuntos. Ensinar respeito às crianças é fundamental para que elas cresçam tendo um saber crítico, entendendo as familiaridades e diferenças entre povos, e assim não 
criando o esdrúxulo hábito de julgar e marginalizar em virtude de cor de pele ou outra característica. Portanto, a escola deve sempre convidar os pais a comparecerem em reuniões e projetos, a fim de prestigiar e incluir todas as culturas, e representações, presentes no vasto repertório acadêmico e cultural do âmbito educacional.

\section{HIPÓTESES DE SOLUÇÃO}

Embasado na análise reflexiva acerca dos pontos apresentados na teorização, é imprescindível pensar em possíveis soluções para apurar o problema da discriminação e estereotipação negra na escola, tendo como princípios uma escola igualitária e com aprendizagem significativa a qualquer pessoa que a ela recorra. Desta forma, é possível apresentar algumas alternativas e possibilidades de solução:

- Realizar atividades extracurriculares, baseadas em representatividades históricoculturais;

- Incentivar a percepção dos alunos acerca das diversas culturas presentes no país;

- Realização de palestras lúdicas sobre a cultura afro-brasileira;

- Propor reuniões palestrais com dinâmicas sobre o tema para reforçar e incentivar os professores a trabalharem mais a temática com os alunos;

- Apresentar peças teatrais para ilustrar aos alunos tamanha importância do respeito com todos;

- Propor feira cultural para que os alunos pesquisem sobre diferentes culturas, raças e etnias para que eles expliquem para outras turmas o que aprenderam;

- Realizar formação continuada para professores com foco na temática em voga;

- Reunir com a família e a escola a fim de que colaborem com esse processo de ensino aprendizagem;

- Propor livros na biblioteca nas escolas para que os alunos tenham mais contato com o tema.

\section{APLICAÇÃO À REALIDADE}

Devido à pandemia (COVID-19) que assolou não somente o Brasil, mas diversos outros países do mundo, não foi possível a realização da aplicação presencialmente, justamente porque todos os campos sociais estão com suas atividades presenciais suspensas. Portanto, este capítulo será realizado de maneira a analisar as propostas das hipóteses de solução, tendo como base uma reflexão sobre as problemáticas e as supostas soluções para tal problema.

Levando em consideração todos os aspectos pesquisados e apresentados, é possível perceber que as questões raciais e a representatividade negra nas escolas ainda são assuntos que precisam de muitas mudanças e reflexões. É recorrente o descaso com os alunos negros, o que pode acarretarem um baixo rendimento escolar, problemas de autoestima, complexos de inferioridade, entre outros problemas causados por esse desmazelo no âmbito escolar.

O aluno negro ou o aluno pobre é absorvido pela rede escolar de maneira diferente do aluno de classe média ou não pobre; uma vez constituída essa clientela, os professores atuam no sentido de reforçar a crença de que os alunos pobres e negros não são educáveis. (VALENTE, 2005, p. 3).

A partir desta situação, e das possibilidades apresentadas nas hipóteses de solução, foi adequado optar pela alternativa de realização de uma feira cultural para que os alunos pesquisem sobre diferentes culturas e etnias e as apresentem diante da escola e comunidade escolar. Sendo interessante trabalhar em uníssono com a formação continuada dos professores a respeito de como abordar as questões raciais em sala de aula. Considera-se a promessa de despertar nos alunos a curiosidade, para desenvolver algo lúdico e diferente do que eles estão habituados a pesquisar e estudar, e consequentemente apresentar para outros alunos.

Pensando que diante dessas hipóteses de solução a visão dos alunos sobre $\mathrm{o}$ sentimento de pertencimento a determinado grupo é compartilhado por quem vive na pele a questão da estereotipação, tornando-se um aspecto essencial 
na construção identitária dos indivíduos envolvidos. A construção de culturas e etnias são puramente sociais, baseando-se nas experiências dos indivíduos por meio de suas histórias. Portanto, torna-se primordial a realização de uma feira para que os alunos vivenciem experiências e compartilhem aprendizados.

Em relação à formação continuada dos professores, se faz necessária devido ao importante conhecimento ao qual os professores precisam ter para tratar de assuntos como os citados nos tópicos abordados. Muitos professores oferecem resistência às propostas de inovação, não se abrindo às novas possibilidades, pois ainda tem a visão deturpada e estereotipada, como uma base metodológica de ensino limitado.

Sabe-se que desconstruir é algo complexo, leva tempo e carece de compromisso e entrega, além da necessidade de pesquisas aprofundadas e experiências de desconstrução de modelos. Por isso, é preciso pontuar a formação continuada dos professores como essencial em um projeto, sendo que é de suma importância que os profissionais da educação tenham a possibilidade $e$ responsabilidade de procurar se aprofundar, e entender, sobre os aspectos e complexidades culturais.

Portanto, o ponto de solução abordado é a construção da feira cultural sobre a cultura e história afrobrasileira, contando com a participação dos alunos de turmas dos anos finais do ensino fundamental (6ㅇ ao 9o anos), e uma proposta de formação continuada com os professores, tendo como foco as maneiras de se ensinar a cultura afrobrasileira de maneira a não estereotipar e discriminar, conseguindo transmitir aos alunos os valores essenciais para construir o pensamento humano e igualitário.

\section{CONSIDERAÇÕES FINAIS}

Tendo em vista a situação epidemiológica, o estudo sofreu algumas alterações acerca de seu planejamento, mas não deixou de acrescentar conhecimento aos autores, que tiveram o desafio que pensar em adaptações e novas formas para realizar a produção.

As observações para a construção da problemática foram feitas através de meios digitais, advinda de questionários, possibilitando perceber que as escolas precisam começar a ter uma preocupação em começar, o quanto antes, a trabalhar a cultura africana e afro-brasileira, pois, de acordo com vários professores que responderam aos questionários, os assuntos relacionados ao tema ainda não são tratados em sua totalidade como pauta em suas escolas.

Percebe-se que o ensino da história africana e afrobrasileira sempre foi deficitário, os livros eram extremamente reduzidos neste aspecto, escondendo a complexidade de informações. A temática era apresentada de forma negativa, e partindo muitas vezes de professores que deveriam ser exemplos para seus alunos. A cultura era citada como componente na formação, mas nunca realmente aprofundada, sendo que a verdadeira educação é instrumento formador de opinião, consciência crítica, e viabilização de mudanças na sociedade.

Certamente tais mudanças não acontecem a curto prazo, no entanto o conhecimento, quando elaborado de forma eficaz, terá grande êxito no alcance aos objetivos educacionais. $O$ docente precisa participar de tais mudanças, estando na linha de frente, exercendo o papel de impulsionar as pessoas a quem ele exerce influência, entendendo que precisa ter a iniciativa de procurar uma formação continuada para suprir as lacunas de conhecimento sobre como ensinar sobre questões raciais e culturais, se livrando de rótulos e estereótipos.

É o papel do professor e da escola formarem pessoas de valores e considerações para com os demais, cidadãos que saibam verdadeiramente de onde surgiram suas raízes e que respeitem e entendam a miscigenação de sua nação.

\section{REFERÊNCIAS}

ARAÚJO, Eliany Alvarenga. A construção social da informação: práticas informacionais no contexto de Organizações Não-Governamentais/ONGs brasileiras. Brasília: Faculdade de Estudos Sociais Aplicados da UnB, 1998. 221 p. (Tese, Doutorado em Ciência da Informação).

BERGER, Peter L.; LUCKMANN, Thomas. A construção social da realidade: tratado de 
sociologia do conhecimento. 3. ed. Petrópolis: Vozes, 1976.

BAKKE, Rachel Rua Baptista. Tem orixá no samba: Clara Nunes e a presença do candomblé e da umbanda na música popular brasileira. Religião \& Sociedade, v. 27, n. 2, p. 85-113, 2007.

BRASIL, Senado Federal. Constituição da república federativa do Brasil. Brasília: Senado Federal, Centro Gráfico, 1988.

BRASIL. Ministério da Educação. Diretrizes Curriculares Nacionais para a Educação das Relações Étnico-Raciais e para o Ensino de História e Cultura Afro-Brasileira e Africana. Parecer CNE/CP 3/2004, homologação publicada no DOU 19/05/2004, Seção 1, p. 19. Resolução CNE/CP 1/2004, publicada no DOU 22/06/2004, Seção 1, p. 11.

BRASIL, Legislação. Lei no 10.639, de 9 de janeiro de 2003. Altera a Lei no 9.394, de 20 de dezembro de 1996, que estabelece as diretrizes e bases da educação nacional, para incluir no currículo oficial da Rede de Ensino a obrigatoriedade da temática "História e Cultura Afro-Brasileira", e dá outras providências. Diário Oficial da União, 2003.

BARBOSA, Rogério Andrade. $\mathbf{O}$ segredo das tranças e outras histórias africanas. São Paulo: Scipione, 2007.

DA SILVA, Jéssica Claudio Batista et al. Discriminação racial e seus reflexos no processo de ensino e aprendizagem. Anais do fórum de iniciação científica do UNIFUNEC, v. 7, n. 7, 2016.

DA SILVA, Maurício Pedro. Novas diretrizes curriculares para o estudo da história e da cultura afro-brasileira e africana: a lei 10.639/03. EccoS Revista Científica, v. 9, n. 1, p. 39-52, 2007.

DOS SANTOS CAVALLEIRO, Eliane. Do silêncio do lar ao silêncio escolar: racismo, preconceito e discriminação na educação infantil. Editora Contexto, 2004.

FREIRE, Paulo. Professora sim, tia não: cartas a quem ousa ensinar. São Paulo: Olho D’Água, 1997.

FLEURI, Reinaldo Matias. Políticas da diferença: para além dos estereótipos na prática educacional. Educação \& Sociedade, v. 27, p. 495520, 2006.

GOMES, N.L. Educação cidadã, etnia e raça: o trato pedagógico da diversidade. In: Racismo e anti- racismo na educação: repensando nossa escola. CAVALLEIRO, Eliane. São Paulo: Summus, 2001.

LIMA, H. K. M. D. A importância de trabalhar o ensino da história e da cultura afro-brasileira e africana em sala de aula. Universidade Federal Da Paraíba, CABACEIRAS, v. 1, n. 1, p. 1-27, dez./2016. Disponível em: https://repositorio.ufpb.br/jspui/handle/12345678 9/3403. Acesso em: 7 jun. 2020.

MARTINS, José de Souza. A dialética do corpo no imaginário popular. Sexta-feira, antropologia, artes, humanidades. São Paulo: Editora Pletora, n. 4, 1999, p. 46-54.

MUNANGA, Kabengele. Negritude: usos e costumes. São Paulo: Ática, 1986.

PATTO, Maria Helena Souza. Estado, ciência e política na Primeira República: a desqualificação dos pobres. Estudos avançados, v. 13, n. 35, p. 167-198, 1999.

PEREIRA, C.; TORRES, A.; ALMEIDA, S. Um estudo de preconceito na representação de sociedades: análise da influência de um discurso justificador de discriminação no preconceito racial. Psicologia: Reflexão e Crítica, 16 (1), 95-107. Disponível em: https://doi.org/10.1590/S010279722003000100010. Acesso em: 19 jun. 2020.

ROCHA, L.C.P. Política Educacional e a Lei 10.639/03: uma reflexão sobre a necessidade de superação de mecanismos ideológicos legitimadores do quando de desigualdades raciais e sócias na sociedade brasileira. In: Costa, Hilton; Silva, Paulo Vinicius Baptista (Orgs.). Notas de história e cultura afrobrasileira. Editora UEPG, Ponta Grossa, 2011.

SOUZA, I. S; MOTTA, F. P. C; FONSECA, D. Estudos sociológicos e antropológicos. São Paulo: Rev. NMH, 2002.

VALENTE, Ana Lúcia. Ação afirmativa, relações raciais e educação básica. Revista Brasileira de Educação, n. 28, p. 62-76, 2005. 